\title{
Doses e épocas de aplicação de potássio no desempenho agronômico do milho no cerrado piauiense
}

\author{
Fabiano André Petter ${ }^{*}$, Fabricio Ribeiro Andrade², Alan Mario Zuffo ${ }^{3}$, \\ Marinete Martins de Sousa Monteiro ${ }^{4}$, Leandro Pereira Pacheco ${ }^{5}$, Fernandes Antônio de Almeida ${ }^{6}$

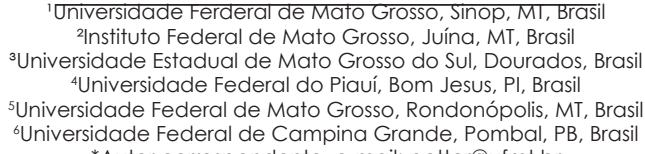

Resumo

Por se tratar de uma fronteira agrícola relativamente nova, o cerrado piaviense ainda necessita de informações quanto ao manejo de adubação potássica, uma vez que, ainda não há uma recomendação técnica de adubação para o milho por parte dos órgãos oficiais de pesquisa. Assim, objetivou-se com esse trabalho avaliar a eficiência de doses e épocas de aplicação de $\mathrm{K}_{2} \mathrm{O}$ na cultura do milho no cerrado piauiense. O trabalho foi conduzido a campo em LATOSSOLO AMARELO distrófico. O delineamento experimental utilizado foi blocos casualizados, com quatro repetições, em esquema fatorial $(4 \times 4)+1$, sendo os tratamentos compostos pela combinação de quatro doses de potássio: $30,60,90$ e $120 \mathrm{~kg}$ de $\mathrm{K}_{2} \mathrm{O} \mathrm{ha}^{-1}+$ testemunha adicional (zero kg de $\mathrm{K}_{2} \mathrm{O} \mathrm{ha}$ I), aplicadas em quatro épocas: $100 \%$ na semeadura; $100 \%$ aos 30 dias após a semeadura (DAS); $50 \%$ na semeadura e 50\% 30 DAS; 50\% 20 DAS e 50\% 40 DAS. Apenas a altura, o diâmetro caulinar e a eficiência agronômica no uso do $\mathrm{K}^{+}$foram influenciados pelas épocas de aplicação de $\mathrm{K}^{+}$, com destaque positivo para a aplicação de 50\% na semeadura e 50\% aos 30 DAS. Com exceção do teor relativo de clorofila e comprimento da espiga, todas as demais variáveis foram influenciadas pelas doses de $\mathrm{K}_{2} \mathrm{O}$. A aplicação de $\mathrm{K}_{2} \mathrm{O}$ proporcionou maiores incrementos nas demais variáveis, sendo a maior resposta para a produtividade de grãos obtida com $53 \mathrm{~kg}$ de $\mathrm{K}_{2} \mathrm{O} \mathrm{ha-1}$.

Palavras-chave: Zea mays L., manejo, adubação potássica

\section{Doses and time of potassium application on corn agronomic performance cultivated in a 'Cerrado' area at Piaui State, Brazil}

\begin{abstract}
Since the 'Cerrado' area of Piaui State, Brazil is a relatively new agricultural frontier, there is lack of information regarding the handling of potassium fertilization, since no information about the better fertilization techniques for this area was provided by the federal research corporations. Thus, the aim of this study was to evaluate the effect of dose and time of application of $\mathrm{K}_{2} \mathrm{O}$ in corn grown in a 'Cerrado' area at the Paui state. The experiment was conducted in a yellow dystrophic oxisol with a completely randomized block design, with four repetitions in a (4x4)+1 factorial. The treatments consisted of combinations of four potassium levels: $30,60,90$ and $120 \mathrm{~kg}, \mathrm{~K}_{2} \mathrm{O} \mathrm{ha-1}+$ additional control (zero $\mathrm{kg} \mathrm{ha}^{-1}$ ) applied in four seasons : $100 \%$ at sowing; $100 \%$ at 30 days after sowing (DAS); $50 \%$ at sowing and 50\% 30 DAS; 50\% 20 DAS and 50\% at 40 DAS. Only the height, stem diameter and agronomic efficiency of the $\mathrm{K}$ use were influenced by the $\mathrm{K}^{+}$time of application, especially with the application of $50 \%$ at sowing and $50 \%$ at 30 DAS. Except for the relative chlorophyll content and ear length, all other variables were influenced by $\mathrm{K}_{2} \mathrm{O}$ doses. The application of $\mathrm{K}_{2} \mathrm{O}$ resulted in greater increases of other evaluatedvariables, mainly for the yield obtained when the dose of $\left(53 \mathrm{~kg} \mathrm{~K}_{2} \mathrm{O}\right.$ ha $^{-1}$ was used,.
\end{abstract}

Keywords: Zea mays L., management, potassium fertilization 


\section{Introdução}

O milho (Zea mays L.) com aproximadamente 140 milhões de hectares é o terceiro cereal mais cultivado no mundo (Fageria et al., 2011 ). No Brasil a área ocupada pelo cereal na safra 2012/2013 foi de aproximadamente 15,9 milhões de hectares distribuídos no cultivo do milho safra e safrinha (CONAB, 2013). O estado do Piauí responde por aproximadamente $5 \%$ da área plantada de milho safra, no entanto, sua participação no cultivo de milho safrinha tem sido praticamente inexistente (CONAB, 2013).

Apesar de incipiente frente a safra brasileira, o cultivo de milho no Cerrado piauiense está em franco processo de expansão, o que vem contribuindo diretamente para o desenvolvimento socioeconômico da região, haja visto que a região apresenta condições edafoclimáticas favoráveis ao cultivo desse cereal (Oliveira Junior et al., 2008). Concomitantemente ao crescimento da área cultivada, há também um aumento no consumo de insumos, dentre os quais, pode-se destacar os fertilizantes, em especial os potássicos.

Entretanto, assim como nas demais regiões do cerrado, os solos desse bioma no estado do Piauí também apresentam de maneira geral, baixa fertilidade natural, elevada acidez, alta saturação por alumínio e baixa saturação por bases, baixa capacidade de troca de cátion (CTC), sendo esta última, devido principalmente aos baixos teores de matéria orgânica (MO) que podem representar a maior parte da CTC (Petter et al., 2012).

No solo, o potássio $\left(\mathrm{K}^{+}\right)$encontra-se disponível na solução, trocável, não trocável e o estrutural (Rabêlo et al., 2013), sendo estes os responsáveis por suprir em parte a demanda das culturas (Otto et al., 2010). Devido à alta solubilidade em água e baixa força de adsorção aos colóides do solo (Duiker \& Beegle, 2006), o parcelamento de doses de $\mathrm{K}_{2} \mathrm{O}$ acima de $50 \mathrm{~kg}$ $\mathrm{ha}^{-1}$ é frequentemente recomendado (Foloni \& Rosolem, 2008), sobretudo em solos arenosos. Essa prática tem como finalidade aumentar a eficiência no uso do nutriente, reduzir as perdas de $\mathrm{K}^{+}$por lixiviação e minimizar o efeito salino do fertilizante sobre as sementes na linha de semeadura (Moterle et al., 2006; Bernardi et al.,
2009).

Diante da dinâmica do $\mathrm{K}^{+}$e das características dos solos do cerrado piaviense, que o tornam insuficiente para suprir as quantidades extraídas pelas culturas em cultivos sucessivos, o manejo da adubação deve ser realizado de maneira a minimizar as perdas e aumentar a eficácia de utilização pelas culturas. Importante destacar, que há recomendações de adubação potássica para algumas regiões do cerrado, todavia, são escassos os estudos para a região do cerrado piaviense, não havendo sequer até o momento qualquer recomendação técnica ou aproximação por parte de órgãos de pesquisa para a aplicação de fertilizantes potássicos na cultura do milho nessa região.

Nesse sentido, aliado ainda ao fato de que há diferenças no uso de fertilizantes na cultura do milho entre as várias regiões do País (Coelho \& França, 2013), e que, recomendações de fertilizantes potássicos não devem ser extrapoladas de uma região para outra, mesmo que dentro do mesmo bioma (Petter et al., 2012), torna-se evidente a necessidade de estudos que possam subsidiar futuras recomendações de manejo e adubação potássica para essa região.

Nesse contexto, objetivou-se com esse trabalho, avaliar o desempenho agronômico do milho em função de doses e épocas de aplicação de potássio na região do cerrado piaviense.

\section{Material e Métodos}

O experimento foi realizado a campo na safra 2011/2012, na Fazenda União (Serra das Laranjeiras) localizada no município de Currais, PI cujas coordenadas pontuais são 08³8'12"' de latitude Sul e 44\%40'11" de longitude Oeste, com altitude média de $550 \mathrm{~m}$. O solo utilizado foi classificado como LATOSSOLO AMARELO - LA, textura franco arenosa (argila: $160 \mathrm{~g} \mathrm{~kg}^{-1}$, silte: $50 \mathrm{~g} \mathrm{~kg}^{-1}$ e areia: $790 \mathrm{~g} \mathrm{~kg}^{-1}$ ), cuja composição química encontra-se na Tabela 1.

O histórico da área é caracterizado pelo cultivo em monocultura da soja desde o ano de 2004, recebendo aplicações anuais de $500 \mathrm{~kg} \mathrm{ha}^{-1}$ de fertilizante NPK 00-20-20. De maneira geral e considerando a classificação 
de fertilidade para o Cerrado da região CentroOeste, esse solo se enquadra como de média fertilidade.

O clima da região é do tipo Aw, segundo a classificação climática global de Köppen, com duas estações bem definidas, sendo uma seca, que vai de maio a setembro, e outra chuvosa, que vai de outubro a abril. Os dados de precipitação e temperatura média ocorrida durante a realização do experimento encontram-se na Figura 1.

Tabela 1. Composição química do solo Latossolo Amarelo distrófico (0-0,20 m) antes da instalação do experimento na região do cerrado piauiense.

\begin{tabular}{|c|c|c|c|c|c|c|c|c|c|c|}
\hline $\mathrm{pH}$ & $\mathrm{Ca}^{2+}$ & $\mathrm{Mg}^{2+}$ & $\mathrm{Al}^{3+}$ & $\mathrm{H}^{+}+\mathrm{Al}^{3+}$ & SB & CTC & P & $\mathrm{K}^{+}$ & MO & V \\
\hline $\mathrm{CaCl}_{2}$ & & - & $--\mathrm{cm}$ & $\mathrm{dm}^{-3}$ & - & & $---m$ & $n^{-3}---$ & $\mathrm{g} \mathrm{kg}^{-1}$ & $\%$ \\
\hline 4,6 & 2,10 & 1,00 & 0,20 & 3,30 & 3,50 & 6,39 & 53,0 & 74,00 & 15,00 & 51,49 \\
\hline
\end{tabular}

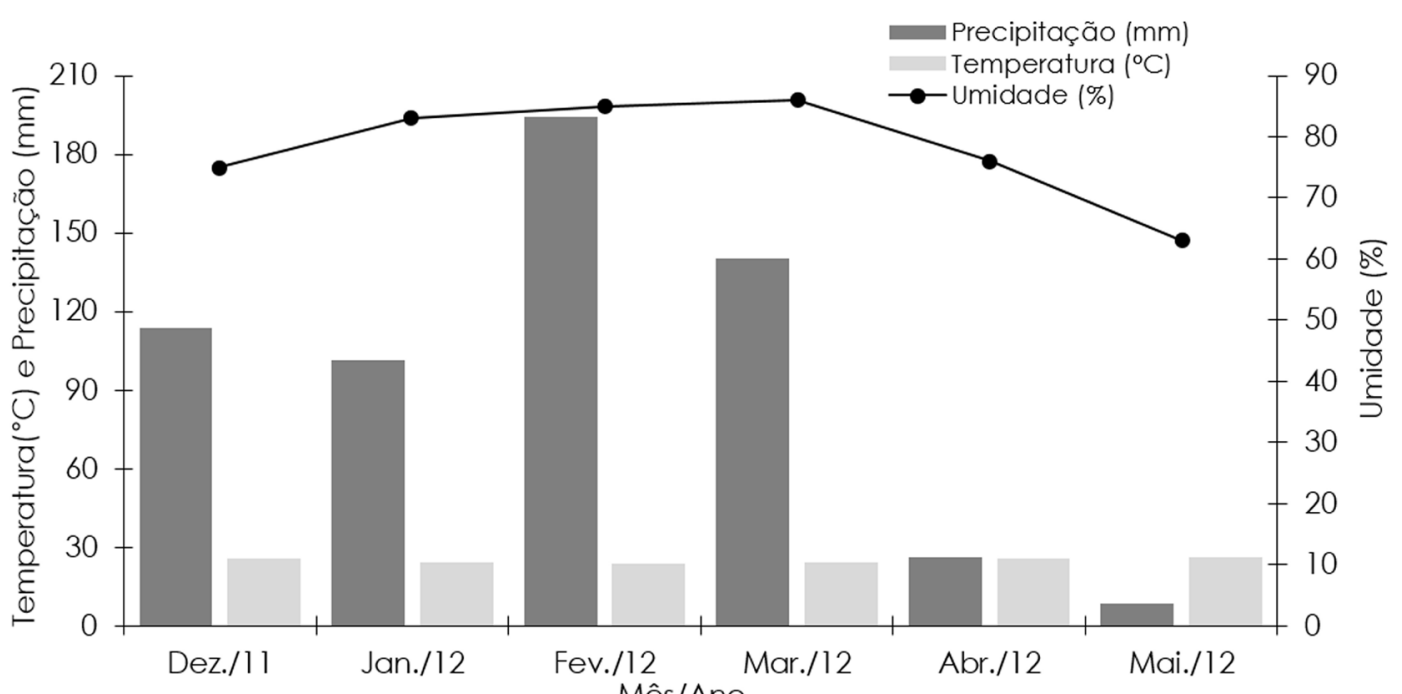

Figura 1. Temperatura média, umidade relativa e precipitação ocorrida na Fazenda União - Currais, PI durante o período de dezembro de 2011 a maio de 2012, na região de Cerrado piaviense (pluviômetro instalado na área e dados da estação meteorológica em Bom Jesus-PI).

O delineamento experimental utilizado foi o de blocos ao acaso, com quatro repetições e 17 tratamentos, dispostos em esquema fatorial incompleto $4 \times 4+1$ com tratamento adicional como controle (sem aplicação: $0 \mathrm{~kg}$ de $\mathrm{K}_{2} \mathrm{O} \mathrm{ha}^{-}$ '). Os demais tratamentos constituíram-se pela combinação de quatro doses de $\mathrm{K}_{2} \mathrm{O}(30 ; 60 ; 90$ e $120 \mathrm{~kg} \mathrm{ha}^{-1}$ ) e quatro épocas de aplicação: 100\% na semeadura; $100 \%$ aos 30 dias após a semeadura; $50 \%$ na semeadura e $50 \%$ aos 30 dias após a semeadura; $50 \%$ aos 20 dias após a semeadura e $50 \%$ aos 40 dias após a semeadura.

A fonte de adubo potássico utilizada foi o cloreto de potássio. Cada parcela foi composta por oito fileiras espaçadas em 0,5 m entre si e com $5 \mathrm{~m}$ de comprimento, totalizando $20,0 \mathrm{~m}^{2}$. Como área útil foram consideradas as quatro linhas centrais, tendo-se desprezado $1 \mathrm{~m}$ em cada extremidade, perfazendo uma área de $6 \mathrm{~m}^{2}$. Para a aplicação dos tratamentos, foram realizadas distribuições manuais a lanço.

A semeadura do milho foi direta, realizada mecanicamente, utilizando-se o híbrido simples Pioneer $30 \mathrm{~F} 35 \mathrm{H}$, de ciclo precoce, na densidade de 60 mil sementes por hectare, previamente tratadas com inseticida Imidacloprido + Thiodicarb, na dose de $45+135 \mathrm{~g}$ de i.a. e fungicida Carbendazim + Thiran na dose de $40+87,5 \mathrm{~g}$ de i.a. por $100 \mathrm{~kg}$ de sementes. No momento da semeadura foram aplicados $70 \mathrm{~kg}$ de $\mathrm{P}_{2} \mathrm{O}_{5}$ ha $^{-1}$ (superfosfato simples) e $20 \mathrm{~kg}$ de $\mathrm{N}$ ha $^{-1}$ (uréia). Quando a cultura atingiu o estágio vegetativo $\vee 6$, procedeu-se a adubação de cobertura, aplicando-se $80 \mathrm{~kg}$ de $\mathrm{N} \mathrm{ha}^{-1}$, tendo como fonte de fertilizante nitrogenado a uréia (45\% N). Não foi realizada calagem.

Antes da semeadura do milho foram aplicados os herbicidas glyphosate e 2,4-D nas 
doses de 1.440 e $806 \mathrm{~g} \mathrm{ha}^{-1}$ i.a., respectivamente. O controle de plantas daninhas em pósemergência foi realizado com o milho no estádio de cinco folhas, utilizando-se o herbicida atrazina, na dose de $1.500 \mathrm{~g} \mathrm{ha}^{-1}$ i.a. No período anterior ao florescimento procedeu-se à aplicação do fungicida Epoxiconazole + Pyraclostrobin na dose de $99,7+87,5 \mathrm{~g}$ de i.a. ha $^{-1}$ associado aos inseticidas Metomil e Imidacloprido + Thiodicarb, na dose de 12,9 e $45+135 \mathrm{~g}$ de i.a. ha $^{-1}$.

No período de pleno florescimento foram determinados os teores de $\mathrm{K}^{+}$na folha, teor relativo de clorofila, altura de plantas, fitomassa seca da parte aérea e diâmetro do colmo. Quando a cultura atingiu a fase de maturidade fisiológica foi avaliada a altura de inserção de espiga e produtividade de grãos. Determinou-se posteriormente o comprimento de espiga (sem palha), número de fileiras por espiga e massa de mil grãos. Foram utilizadas cinco plantas e espigas por parcela para mensuração das variáveis acima descritas. A determinação do teor de $\mathrm{K}^{+}$foliar foi realizada em pleno florescimento através da coleta da folha diagnóstico, localizada na região oposta a inserção da espiga em cinco plantas de cada parcela, que posteriormente foram secas em estufa de circulação forçada a $60^{\circ} \mathrm{C}$, por 72 horas, moídas em moinho Willey equipado com peneira de 40 mesh, sendo à determinação do $\mathrm{K}^{+}$foliar realizada pelo método de digestão em solução nitro-perclórica e determinadas por fotometria de chama. A colheita de grãos foi realizada em toda a área útil da parcela, onde as espigas foram trilhadas mecanicamente e a produção transformada em $\mathrm{kg} \mathrm{ha}^{-1}$ de grãos, padronizado a $13 \%$ de umidade.

O teor relativo de clorofila, foi mensurado utilizando-se clorofilômetro (clorofilLOG CFL 1030), com avaliação do ponto central da folha diagnóstico, localiza na região oposta a espiga. Para a determinação da fitomassa seca da parte aérea as plantas foram levadas à estufa de circulação forçada a $60^{\circ} \mathrm{C}$, até obtenção do peso constante.

Determinou-se a eficiência agronômica: produção econômica obtida (grãos, no caso de culturas anuais) por unidade de nutriente aplicado, a partir da seguinte equação.
$(E A)=(P G c a-P G s a) /(Q N a),\left(\mathrm{kg} \mathrm{kg}^{-1}\right)$

em que: EA e a eficiência agronômica; PGca é a produção, em kg, com adubação; PGsa é a produção, em kg, sem adubação; QNa é a quantidade de nutriente aplicado, em $\mathrm{kg}$.

Determinou-se também 0 índice de colheita de grãos da seguinte forma: ICG = produtividade de grãos/produtividade de grãos + palha.

Após a análise de variância e, no caso de haver significância $(p<0,05)$, os fatores qualitativos foram comparados pelo teste de Tukey $(p<0,05)$, utilizando o programa computacional SISVAR, enquanto os fatores quantitativos foram submetidos à análise de regressão polinomial utilizando o programa computacional SigmaPlot.

\section{Resultados e Discussão}

Com exceção da altura de plantas, diâmetro caulinar e eficiência agronômica no uso do $\mathrm{K}^{+}$, as demais variáveis não foram significativamente influenciadas pelas épocas de aplicação do $\mathrm{K}_{2} \mathrm{O}$ (Tabela 2). Kalpana \& Krishnarajan (2002) verificaram efeito significativo das épocas de aplicação de $\mathrm{K}_{2} \mathrm{O}$ na altura de plantas e fitomassa seca da parte aérea do milho, corroborando em parte com os resultados do presente estudo.

A inexistência do efeito significativo das épocas de aplicação de $\mathrm{K}^{+}$nos parâmetros citados pode ser atribuída à utilização pela cultura do milho, das reservas de K-trocável do solo, uma vez que os teores disponíveis de $\mathrm{K}^{+}$ no solo estavam acima de $70 \mathrm{mg} \mathrm{dm}^{-3}$, sendo considerado como adequado para a região dos Cerrados (Tabela 1). De acordo com Petter et al. (2012) nessas condições de solo no cerrado piaviense, a opção de se fazer a aplicação do $K^{+}$ de forma total ou parcelada na semeadura deve ser em função dos custos e/ou da otimização das operações de aplicação. Entretanto, os referidos autores alertam sobre a utilização de doses elevadas de $\mathrm{K}_{2} \mathrm{O}$, principalmente em função do efeito salino do sal cloreto que poderá ocasionar redução na germinação, se ocorrer períodos de déficit hídrico posterior a semeadura.

A aplicação do $\mathrm{K}^{+}$com $50 \%$ na 
semeadura e 50\% 30 DAS apresentou o maior incremento em altura de plantas de milho (Tabela 2). Tais resultados diferem dos obtidos por Rabêlo et al. (2013) que não verificaram diferenças na altura de plantas quando as doses de potássio foram aplicadas somente na semeadura ou parcelada. Essas diferenças podem ser atribuídas

Tabela 2. Características agronômicas e fisiológicas do milho em função das épocas de aplicação de potássio. Currais-PI, safra $2011 / 2012$.

\begin{tabular}{|c|c|c|c|c|}
\hline Época & $\begin{array}{l}\text { Altura plantas } \\
(\mathrm{cm})\end{array}$ & $\begin{array}{l}\text { Altura de inserção da } \\
\text { espiga (cm) }\end{array}$ & K Foliar & Clorofila total \\
\hline $100 \% \mathrm{~S}$ & $274,22 a b^{*}$ & $152,6^{\text {ns }}$ & $22,15^{\text {ns }}$ & 62,60 ns \\
\hline $50 \% S+50 \% 30$ DAS & 276,96 a & 153,40 & 22,50 & 60,50 \\
\hline $100 \% 30$ DAS & $275,69 a b$ & 150,80 & 21,80 & 62,10 \\
\hline $50 \% 20$ DAS + 50\% 40 DAS & $269,77 \mathrm{~b}$ & 149,75 & 22,60 & 61,55 \\
\hline $\mathrm{CV}$ & 2,76 & 3,78 & 17,60 & 6,25 \\
\hline Época & $\begin{array}{l}\text { Fitomassa seca } \\
\left.\text { (g planta }{ }^{-1}\right)\end{array}$ & $\begin{array}{l}\text { Diâmetro caulinar } \\
\text { (mm) }\end{array}$ & $\begin{array}{l}\text { Número de } \\
\text { fileiras por } \\
\text { espiga }\end{array}$ & $\begin{array}{l}\text { Comprimento } \\
\text { de espiga }(\mathrm{cm})\end{array}$ \\
\hline $100 \% \mathrm{~S}$ & $127,70^{\mathrm{ns}}$ & $21,95 \mathrm{ab}^{*}$ & $16,95^{\mathrm{ns}}$ & $14,05^{\text {ns }}$ \\
\hline $50 \% S+50 \% 30$ DAS & 135,50 & $22,05 \mathrm{a}$ & 17,00 & 14,15 \\
\hline $100 \% 30$ DAS & 132,15 & $21,15 \mathrm{~b}$ & 16,90 & 13,60 \\
\hline $50 \% 20$ DAS + 50\% 40 DAS & 128,55 & $21,35 a b$ & 16,45 & 14,05 \\
\hline $\mathrm{CV}$ & 12,30 & 4,96 & 4,59 & 6,93 \\
\hline Época & $\begin{array}{l}\text { Peso de mil grãos } \\
\text { (g) }\end{array}$ & $\begin{array}{c}\text { Produtividade } \\
\text { de grãos } \\
\left(\mathrm{kgha}^{-1}\right)\end{array}$ & $\begin{array}{c}\text { Eficiência } \\
\text { aggronômica } \\
\left(\mathrm{kg} \mathrm{kg}^{-1}\right)\end{array}$ & ICG \\
\hline $100 \% \mathrm{~S}$ & $257,75^{\mathrm{ns}}$ & 6402 ns & $14,08 b^{*}$ & $0,47^{\mathrm{ns}}$ \\
\hline $50 \% S+50 \% 30$ DAS & 258,40 & 6266 & 19,87 a & 0,45 \\
\hline $100 \% 30$ DAS & 256,45 & 6591 & $17,62 a b$ & 0,47 \\
\hline $50 \% 20$ DAS + 50\% 40 DAS & 256,45 & 6101 & $15,06 \mathrm{~b}$ & 0,45 \\
\hline $\mathrm{CV}$ & 3,26 & 10,94 & 24,90 & 8,84 \\
\hline
\end{tabular}

Embora não tenha havido efeito significativo das épocas de aplicação para a maioria dos parâmetros avaliados, houve efeito para a eficiência agronômica no uso do $\mathrm{K}^{+}$, fato este, que pode reduzir os custos de produção em função do manejo de adubação, uma vez que, podem-se utilizar adubações com taxas menores, mas sempre de acordo com a necessidade da cultura nas condições edafoclimáticas cultivadas. Esses resultados evidenciam que aplicações parceladas do nutriente tendem a ser mais responsivas devido a elevada necessidade desse nutriente ao longo do desenvolvimento da cultura, fato este, comprovado por Von Pinho et al. (2009) que observaram picos de absorção do referido nutriente durante o crescimento vegetativo, enchimento de grãos e maturidade fisiológica de duas cultivares de milho.

Considerando-se a máxima produtividade estimada neste estudo, que é de ao tipo às condições edfoclimáticas das regiões de estudo. O menor diâmetro de coleto de plantas de milho verificado com a aplicação de todo $\circ \mathrm{K}_{2} \mathrm{O}$ aos 30 DAS, se deve ao fato da alta demanda do $\mathrm{K}$ nos primeiro 30 dias (Borin et al., 2010). 
aplicadas (Figura 2a). Todavia, esse aumento nas concentrações de $\mathrm{K}^{+}$nas folhas não influenciou o teor relativo de clorofila total (Figura 2b), evidenciando não haver correlação direta entre níveis de $\mathrm{K}^{+}$nas folhas e síntese de
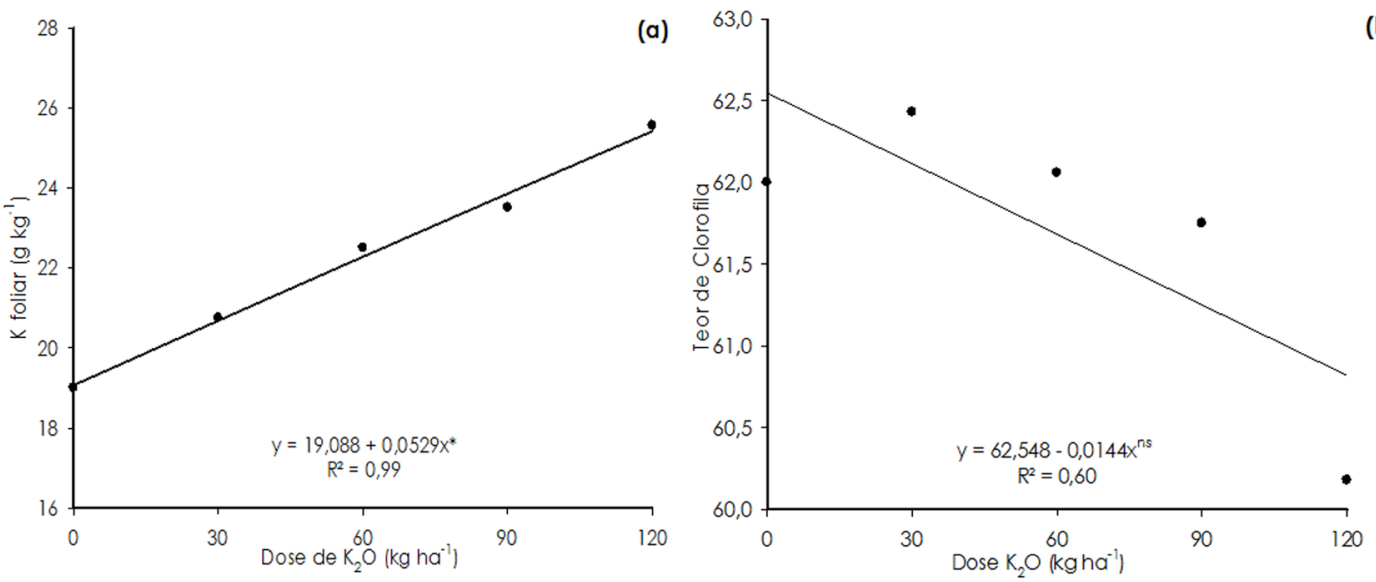

Figura 2. Teor de $\mathrm{K}$ ( $\mathrm{a}$ ) e teor relativo de clorofila (b) nas folhas de plantas de milho em função de doses de potássio no cerrado piauiense. ns não significativo; ** e * significativo a 1 e $5 \%$ de probabilidade pelo teste "t" de Student, respectivamente. Currais-PI, safra 2011/2012.

A ausência de efeito significativo das doses de $\mathrm{K}_{2} \mathrm{O}$ nos teores de clorofila corroboram com os dados obtidos por Sousa et al. (2010) que não verificaram efeito da aplicação de $\mathrm{K}^{+}$nos teores de clorofila em plantas de milho. Diversos trabalhos (Ferreira et al., 2006; Viana \& Kiehl, 2010) têm demonstrado correlações positivas entre os teores de clorofila obtidos com clorofilômetro apenas com a concentração de nitrogênio nas clorofila. Aumento no teor de $\mathrm{K}^{+}$em plantas de milho também foi verificado por Valderrama et al. (2011) com a aplicação de doses crescentes de potássio.

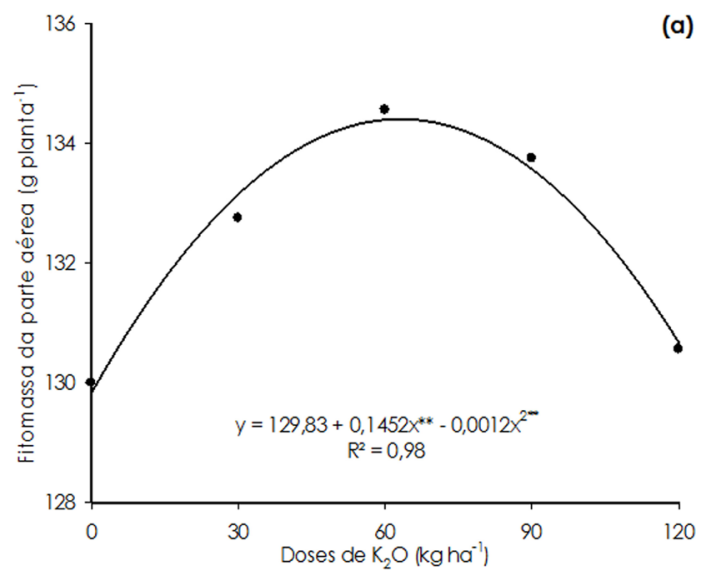

folhas, o que é devido ao papel do nitrogênio na síntese de clorofila (Debaeke et al., 2006).

A fitomassa seca da parte aérea (Figura 3a) e diâmetro caulinar (Figura 3b) de plantas de milho foram influenciados significativamente pelas doses de $\mathrm{K}_{2} \mathrm{O}$, sendo que para ambos os parâmetros houve comportamento semelhante, em que o modelo quadrático melhor se ajustou aos dados.

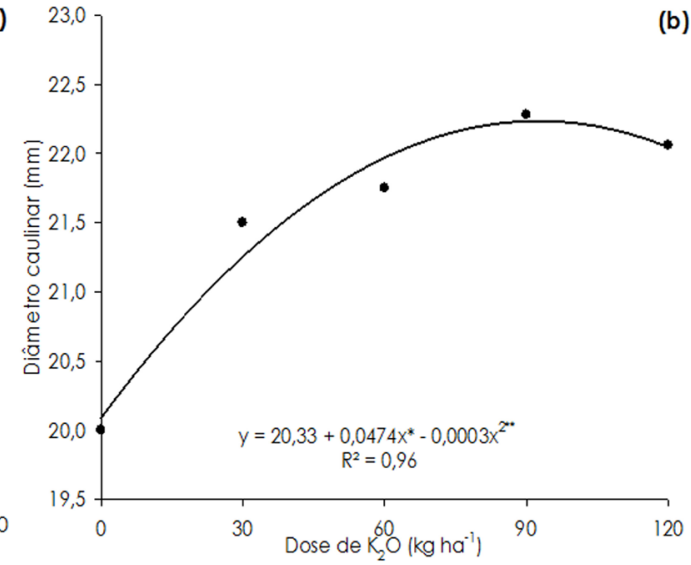

Figura 3. Fitomassa da parte aérea (a) e diâmetro caulinar (b) de milho em função de doses de potássio no cerrado piauiense. ns não significativo; ** $e^{*}$ significativo a 1 e $5 \%$ de probabilidade pelo teste "t" de Student, respectivamente. Currais-PI, safra 2011/2012.

A máxima fitomassa da parte aérea $(132,2 \mathrm{~g})$ e diâmetro do colmo $(22,2 \mathrm{~mm})$ nas plantas de milho foram verificados nas doses de 60 e $79 \mathrm{~kg} \mathrm{ha}^{-1}$ de $\mathrm{K}_{2} \mathrm{O}$ respectivamente. Ebrahimi et al. (2011) observaram incremento na fitomassa e diâmetro de coleto de plantas de milho com o aumento da dose de $\mathrm{K}_{2} \mathrm{O}$, enquanto que, Rabêlo et al. (2013) não observaram diferença 
na produção de fitomassa com as doses de $\mathrm{K}_{2} \mathrm{O}$, apenas uma tendência de maior produção de fitomassa utilizando $90 \mathrm{~kg} \mathrm{ha}^{-1}$ de $\mathrm{K}_{2} \mathrm{O}$. Este fato pode estar associado ao aumento do influxo de $\mathrm{CO}_{2}$, pelo fato do $\mathrm{K}^{+}$interferir na regulação osmótica, promovendo assim maior tempo de abertura estomática e consequentemente aumentando a taxa fotossintética das plantas que resulta em maior produção carboidratos (Ebrahimi et al., 2011) e consequentemente maior produção de fitomassa.

O maior diâmetro do colmo com incremento das doses de $\mathrm{K}_{2} \mathrm{O}$ também foi observado por Andreotti et al. (2001), o incremento do diâmetro de coleto constitui um fator importante do ponto de vista fisiológico, haja vista que o colmo não possui apenas função de sustentação de folhas e inflorescências, mas principalmente, como uma estrutura destinada ao armazenamento de sólidos solúveis que são

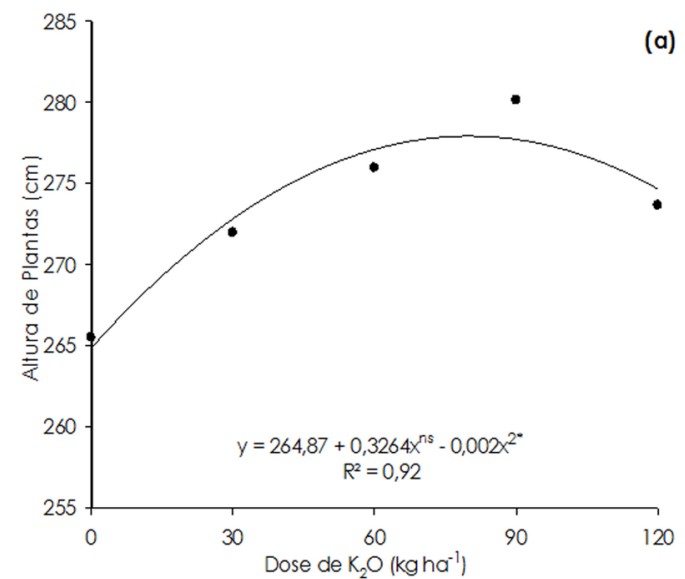

utilizados posteriormente na formação dos grãos (Carmo et al., 2012) através da mobilização das reservas, além de reduzir o acamamento das plantas, ocasionando assim menores perdas dos grãos no ato de colheita.

Verificou-se diferença significativa entre as doses de $\mathrm{K}_{2} \mathrm{O}$ aplicadas para a altura de plantas de milho (Figura 4a) altura de inserção de espiga (Figura 4b), em que os modelos quadráticos e linear melhor se ajustaram aos dados observados respectivamente. A altura máxima de plantas de milho $(278 \mathrm{~cm})$ foi obtida com a dose estimada de $82 \mathrm{~kg}$ de $\mathrm{K}_{2} \mathrm{O} \mathrm{ha}^{-1}$, esses resultados corroboram com os observados por Rabêlo et al. (2013) onde os dados observados se ajustaram ao modelo quadrático e a máxima altura de plantas $(281 \mathrm{~cm})$ foi observada com a dose estimada de $97 \mathrm{~kg}$ de $\mathrm{K}_{2} \mathrm{O} \mathrm{ha}^{-1}$, valores bem próximos dos encontrados no presente estudo.

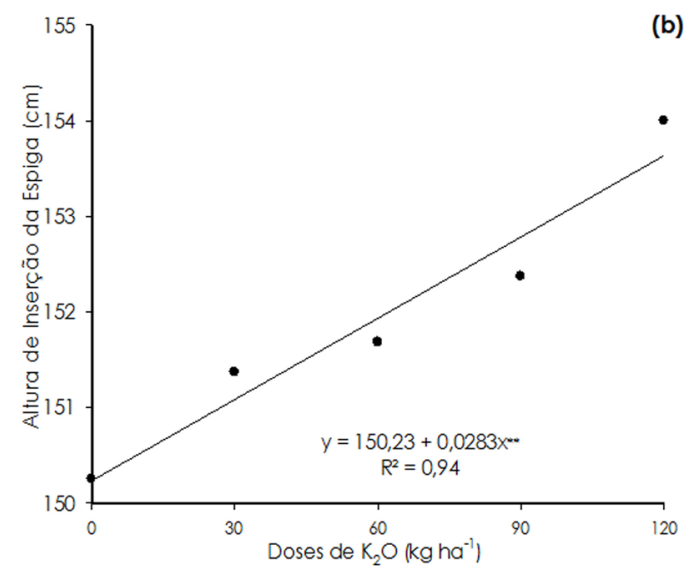

(b)

(b) Altura de plantas (a) e altura de inserção da espiga (b) de miho em função de doses de potássio no cerrado piauiense. ${ }^{\text {ns }}$ não significativo; ** $e^{*}$ significativo a 1 e $5 \%$ de probabilidade pelo teste " $t$ " de Student, respectivamente. Currais-PI, safra $2011 / 2012$.

A maior altura de inserção de espiga, ocasionada pelo incremento das doses de $\mathrm{K}_{2} \mathrm{O}$ deve-se principalmente, ao comportamento semelhante da altura de plantas, onde plantas maiores tendem a apresentar maior altura de inserção da espiga. Essa característica de maior altura de inserção da espiga é desejável do ponto de vista operacional, pois proporciona vantagens significativas na colheita mecanizada (Possamai et al., 2001) e econômicas pelo fato de reduzir perdas e aumentar a pureza dos grãos, principalmente em cultivos consorciados com espécies do gênero Brachiaria em sistemas de integração lavoura-pecuária.
A reposta da altura das plantas e altura de inserção de espigas de milho em função das doses de $\mathrm{K}_{2} \mathrm{O}$ pode estar relacionada ao fato de que $0 \mathrm{~K}^{+}$pode influenciar indiretamente na melhoria do uso do $\mathrm{N}$ por meio da ativação enzimática, proporcionando maior divisão e expansão celular e interferindo positivamente no processo fotossintético.

Para o número de fileiras por espiga de milho (Figura $5 a$ ) $\circ$ modelo quadrático evidenciou os maiores valores $(p<0,05)$ na dose de $90 \mathrm{~kg}$ de $\mathrm{K}_{2} \mathrm{O} \mathrm{ha}{ }^{-1}$. E para o comprimento de espiga, apesar de haver uma tendência de aumento, não houve efeito significativo das doses aplicadas (Figura $5 b$ ). 

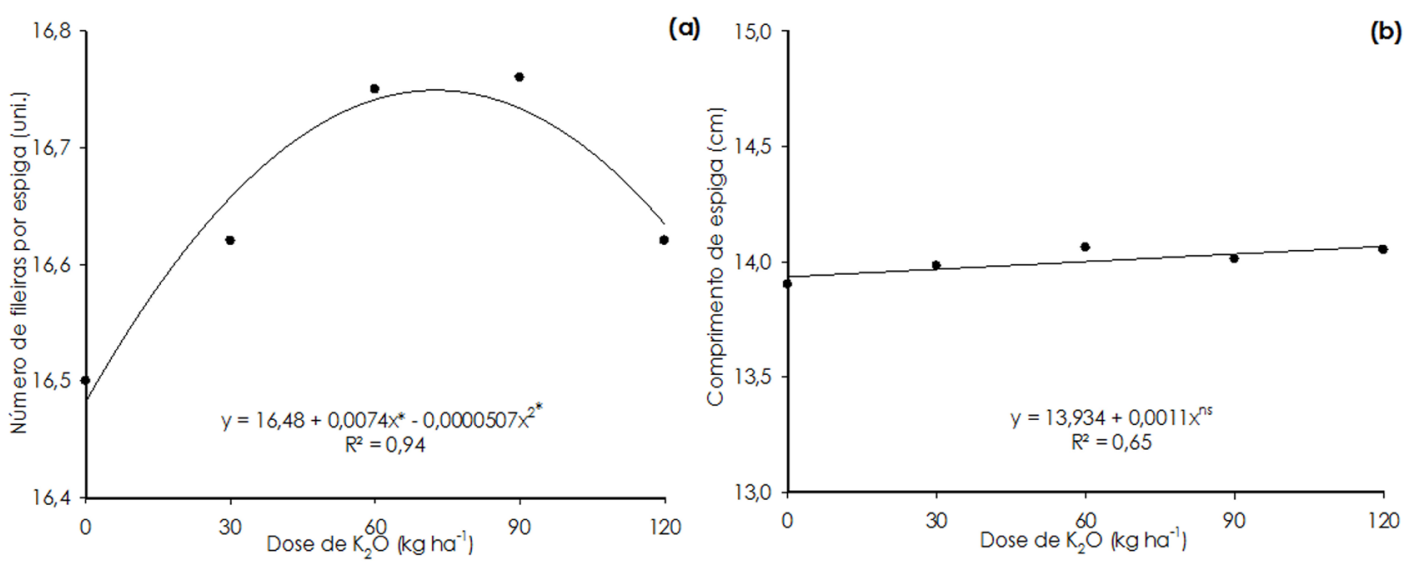

Figura 5. Número de fileiras por espiga (a) e comprimento da espiga (b) de plantas de milho em função de doses de potássio no cerrado piauiense. ${ }^{\text {ns }}$ não significativo; * significativo a $5 \%$ de probabilidade pelo teste "t" de Student. Currais$\mathrm{Pl}$, safra $2011 / 2012$.

O aumento do número de fileiras por espiga é importante do ponto de vista produtivo, pois segundo Kappes et al. (2009) esse parâmetro é um dos caracteres que pode interferir, diretamente no número de grãos por fileira, e, consequentemente, na produtividade final.

A aplicação de doses crescentes de $\mathrm{K}_{2} \mathrm{O}$ proporcionou decréscimo linear significativo na massa de mil grãos (Figura 6a). Resultados semelhantes foram verificado por Valderrama et al. (2011), em que o incremento de doses de $\mathrm{K}_{2} \mathrm{O}$ resultou em menor massa de mil grãos. A redução na massa de grãos pode ser perfeitamente compreendida, à medida que houve maior número de fileiras por espiga, e, consequentemente maior número de grãos, o que fisiologicamente tende a resultar em grãos com menor massa, uma vez que, aumenta-se a competição de fotoassimilados no interior da espiga.
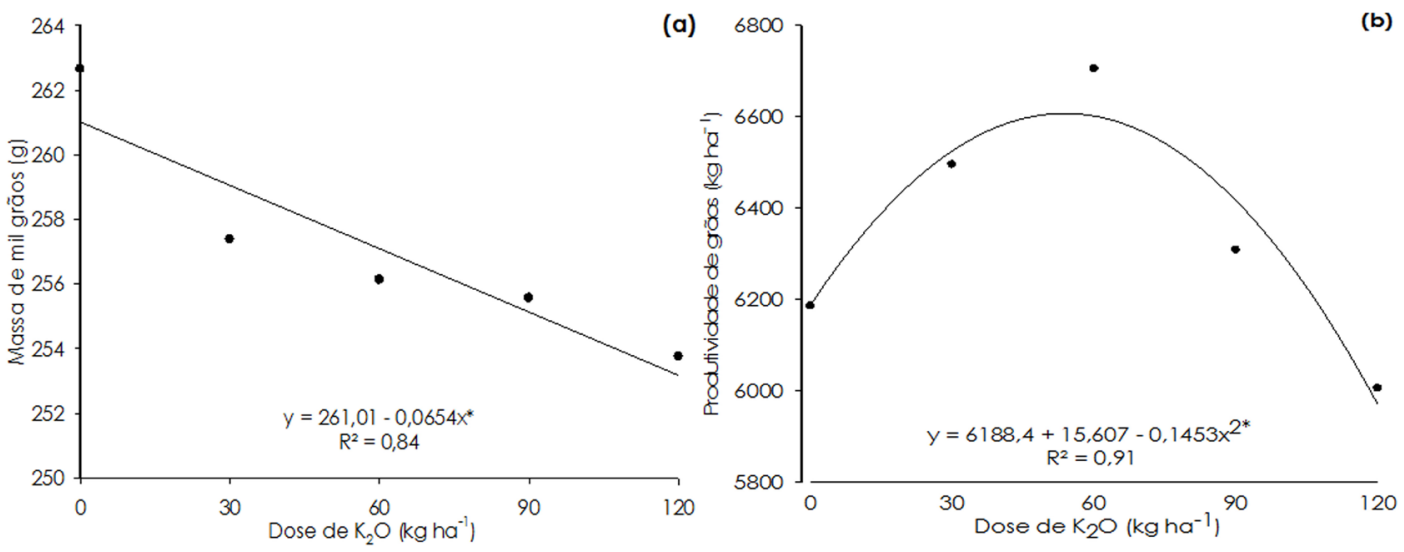

Figura 6. Massa de mil grãos (a) e produtividade de grãos (b) de milho em função de doses de potássio no cerrado piauiense. "ns não significativo; ${ }^{* *} e^{*}$ significativo a 1 e $5 \%$ de probabilidade pelo teste "t" de Student, respectivamente. Currais-Pl, safra 2011/2012.

A produtividade de grãos fol significativamente influenciada pelas doses de $\mathrm{K}_{2} \mathrm{O}$ aplicadas (Figura 6b). A máxima produtividade de grãos ou máxima eficiência técnica obtida foi de $6.607 \mathrm{~kg} \mathrm{ha}^{-1}$, utilizando a dose estimada de $53 \mathrm{~kg} \mathrm{ha}^{-1}$ de $\mathrm{K}_{2} \mathrm{O}$, o que representa uma produtividade de sete sacas superior à testemunha. Esses resultados diferem dos obtidos por Pavinato et al. (2008) que não verificaram efeito da aplicação de $\mathrm{K}^{+}$na produtividade de grãos do milho, todavia, corroboram os obtidos por Niu et al. (2013), que verificaram diferenças significativas na produtividade de grãos de milho com a aplicação de doses de $\mathrm{K}_{2} \mathrm{O}$.

Em número relativo, esse ganho 
produtivo representa pouco quando comparado ao ganho promovido por outros nutrientes como o nitrogênio, porém, apesar desse nutriente encontrar-se em nível adequado no solo, o manejo da adubação proporcionou ganhos satisfatórios na produtividade com uma adubação abaixo do normalmente utilizado pelos produtores na prática, que é de 80 a 100 $\mathrm{kg}$ de $\mathrm{K}_{2} \mathrm{O} \mathrm{ha}^{-1}$. Outro aspecto a ser considerado é o benefício ambiental que a redução das doses de $\mathrm{K}_{2} \mathrm{O}$ proporciona sem a redução de produtividade.

A eficiência agronômica no uso do $\mathrm{K}^{+}$ apresentou decréscimo exponencial com $\mathrm{O}$ acréscimo nas doses de $\mathrm{K}_{2} \mathrm{O}$ aplicadas (Figura 7a), ou seja, à medida que se aumentam as doses, as respostas em produtividade de grãos não seguem a mesma tendência em proporção.
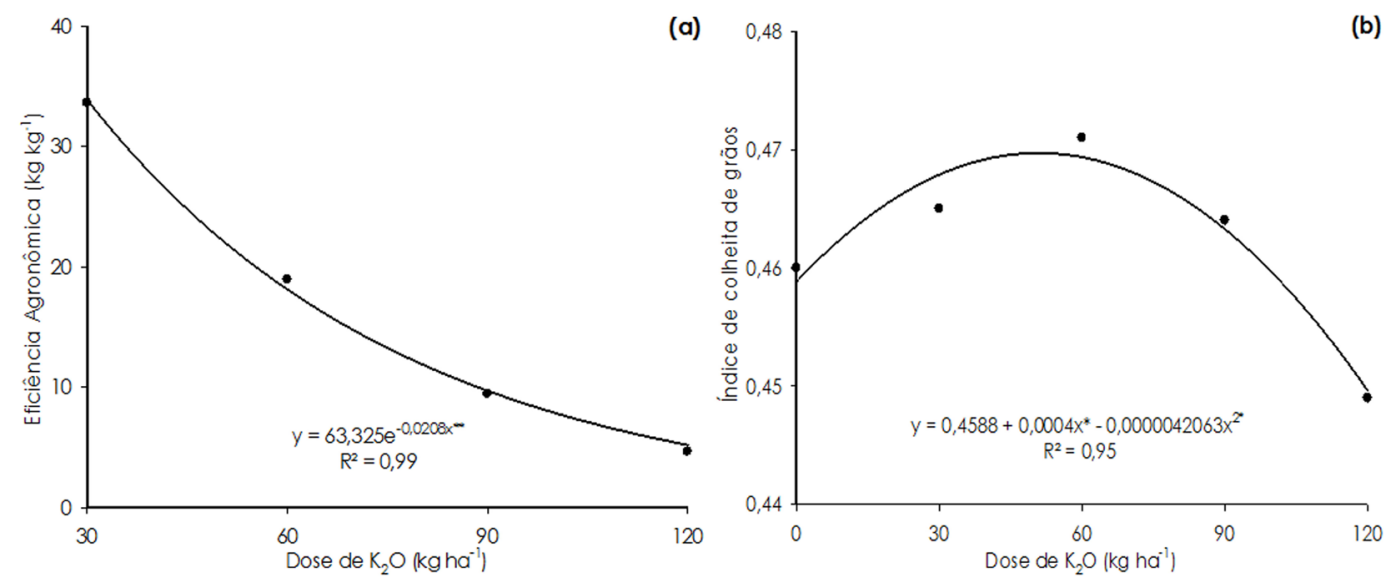

Figura 7. Eficiência agronômica (a) e índice de colheita de grãos (b) de milho em função de doses de potássio no cerrado piauiense. ns não significativo; ** e * significativo a 1 e $5 \%$ de probabilidade pelo teste "t" de Student, respectivamente. Currais-PI, safra $2011 / 2012$

A maior eficiência agronômica no uso do $\mathrm{K}^{+}$foi verificada com a aplicação de $30 \mathrm{~kg}$ de $\mathrm{K}_{2} \mathrm{O} \mathrm{ha}^{-1}$, indicando que a dose aplicada que proporcionou maior produtividade (53 kg ha-1) não foi a mesma dose que proporcionou maior eficiência agronômica. Comparativamente, esses dados assemelhamse com os apresentados por Deparis et al. (2007), que também verificaram redução da eficiência no uso do K com aplicações acima de $30 \mathrm{~kg}$ de $\mathrm{K}_{2} \mathrm{O} \mathrm{ha-1}$. Esses resultados reforçam a lei dos rendimentos decrescentes de Mitscherlich, a qual afirma que à medida que se aumenta a dose de um determinado fertilizante, a resposta em produtividade é reduzida de forma exponencial.

$\square$ índice de colheita de grãos (ICG) foi significativamente influenciado pelas doses de $\mathrm{K}_{2} \mathrm{O}$ aplicadas (Figura $7 \mathrm{~b}$ ), onde o modelo quadrático foi o que melhor se ajustou aos dados, seguindo a tendência da maioria dos parâmetros analisados, com $\bigcirc$ maior valor estimado para tal índice $(0,7)$ obtido com a aplicação de $48 \mathrm{~kg}$ de $\mathrm{K}_{2} \mathrm{O} \mathrm{ha-1}$. Esses resultados evidenciam que houve boa translocação de fotoassimilados das folhas para os grãos, ou seja, a eficiência de conversão de fitomassa em grãos foi satisfatória, demonstrando estar dentro da faixa proposta pelos respectivos autores para cultivares de alta produtividade.

O índice de colheita de grãos consiste na fração dos grãos produzidos em relação à produção de matéria seca da parte aérea da planta, a utilização deste índice permite identificar a habilidade de um cultivar em combinar elevada capacidade de produção total e de destinar a matéria seca acumulada para componentes de interesse econômico, neste caso a produção de grãos (Dourado Neto \& Fancelli, 2000). Segundo os mesmos autores 0 índice de colheita de grãos pode variar de 0,60 para cultivares de alta produtividade a 0,10 para cultivares de baixa produtividade. De acordo com Gava et al. (2010) o ICG é comumente empregado em avaliações de genótipos submetidos a diferentes tipos de tratamentos e em condições climáticas contrastantes.

Os resultados controversos observados no presente estudo, quanto às épocas de aplicação e a doses de $\mathrm{K}_{2} \mathrm{O}$ a serem utilizadas em solos na região dos cerrados reforçam a 
necessidade de se definir a adubação potássica em função das condições edafoclimáticas especíícas de cada região, não podendo extrapolar recomendações de fertilizantes de outras regiões, mesmo que dentro do mesmo bioma conforme reportado por Petter et al. (2012).

\section{Conclusões}

Aplicações de potássio parceladas em LATOSSOLO AMARELO do cerrado piauiense proporcionaram maior eficiência agronômica no uso do nutriente, diâmetro caulinar e altura de plantas de milho, com destaque para a aplicação de $50 \%$ na semeadura e o restante em cobertura aos 30 dias após a semeadura.

Os maiores valores de fitomassa seca, índice de colheita e produtividade de grãos são verificados com a aplicação de 48 a $60 \mathrm{~kg}$ de $\mathrm{K}_{2} \mathrm{O} \mathrm{ha-1}$.

\section{Referências}

Andreotti, M., Rodrigues, J.D., Crusciol, A.C.C. Souza, E.C.A., Büll, L.T. 2001. Crescimento do milho em função da saturação por bases e da adubação potássica. Scientia Agricola 58(1): 145-150.

Bernardi, A.C.C., Oliveira Júnior, J.P., Leandro, W.M., Mesquita, T.G.S., Freitas, P.L., Carvalho, M.C.S. 2009. Doses e formas de aplicação da adubação potássica na rotação soja, milheto e algodão em sistema plantio direto. Pesquisa Agropecuária Tropical 39(2): 158-167.

Borin, A.L.D.C., Lana, R.M.Q., Pereira, H.S. 2010. Absorção, acúmulo e exportação de macronutrientes no milho doce cultivado em condições de campo. Ciência e Agrotecnologia 34(Edição Especial): 1591-1597.

Carmo, M.S., Cruz, S.C.S., Souza, E.J., Campos, L.F.C., Machado, C.G. 2012. Doses e fontes de nitrôgenio no desenvolvimento e produtividade da cultura de milho doce (Zea mays convar. saccharata var. rugosa). Bioscience Journal 28(Supplement 1): 223-231.

Coelho, A.M., França, G.E. 2013. Nutrição e adubação do milho. Sete Lagoas, Embrapa Milho e Sorgo, p. 1- 17.

CONAB - COMPANHIA NACIONAL DE ABASTECIMENTO. 2013. Acompanhamento de safra brasileira: Grãos, $2^{\circ}$ Levantamento, Brasília, CONAB, p. 1-80.

Debaeke, P., Rouet, P., Justes, E. 2006. Relationship between the normalized SPAD index and the nitrogen nutrition index: application to durum wheat. Journal of Plant Nutrition 29(1): 75-92.

Deparis, G. A., Lana, M. do C., Frandoloso, J. F. 2007. Espaçamento e adubação nitrogenada e potássica em cobertura na cultura do milho. Acta Scietiarum Agronomy 29:517-525.

Dourado Neto, D., Fancelli, A.L. 2000. Produção de milho. Guaíba, Agropecuária, 360p.

Duiker, S.W., Beegle, D.B. 2006. Soil fertility distributions in long-term no-till, chisel/disk and moldboard plow/disk systems. Soil Tillage Research 88(1-2): 30-41.

Ebrahimi, S.T., Yarnia, M., Benam, M.B.K., Tabrizi, E.F.M. 2011. Effect of potassium fertilizer on corn yield (Jeta Cv .) under drought stress condition. American Journal of Environmental Sciences 10(2): 257-263.

Fageria, N.K., Baligar, V.C., Jones, C.A. 2011. Corn. In: Fageria, N.K., Baligar, V.C., Jones, C.A. Growth and mineral nutrition of field crops. $3^{\mathrm{a}} \mathrm{ed}$. Madison, Marcel Decker, p. 313-342.

Ferreira, M.M.M., Ferreira, G.B., Fontes, P.C.R., Dantas, J.P. 2006. Índice SPAD e teor de clorofila no limbo foliar do tomateiro em função de doses de nitrogênio e da adubação orgânica, em duas épocas de cultivo. Revista Ceres 53(305): 83-92.

Foloni, J.S.S., Rosolem, C.A. 2008. Produtividade e acúmulo de potássio na soja em função da antecipação da adubação potássica no sistema plantio direto. Revista Brasileira de Ciência do Solo 32(4): 1549-1561.

Gava, G.J.C., Oliveira, M.W., Silva, M.A., Jerônimo, E.M., Cruz, J.C.S., Trivelin, P.C.O. 2010. Produção de fitomassa e acúmulo de nitrogênio em milho cultivado com diferentes doses de $15 \mathrm{~N}$-uréia. Semina: Ciências Agrárias 31 (4): 851-862.

Kalpana, R., Krishnarajan J. 2002. Effect of dose and time of potassium application on yield and quality of baby corn. Agricultural Science Digest 22(1): 59-60.

Kappes, C., Carvalho, M.A.C., Yamashita, O.M., Silva, J.A.N. 2009. Influência do nitrogênio no desempenho produtivo do milho cultivado na segunda safra em sucessão à soja. Pesquisa Agropecuária Tropical 39(3): 251-259.

Moterle, L.M., Lopes, P.C., Braccini, A.L. Scapim, C.A. 2006. Germinação de sementes e crescimento de plântulas de cultivares de milhopipoca submetidas ao estresse hídrico e salino. Revista Brasileira de Sementes 28(3): 169-176.

Niu, J., Zhang, W., Ru, S., Chen, X., Xiao, K., Zhang, 
X., Assaraf, M., Imas, P., Magen, H., Zhang, F. 2013. Effects of potassium fertilization on winter wheat under different production practices in the North China Plain. Field Crops Research 140: 69-76.

Oliveira Junior, A., Prochnow, L.I., Klepker, D. 2008. Eficiência agronômica de fosfato natural reativo na cultura da soja. Pesquisa Agropecuária Brasileira 43(5): 623-631.

Otto, R., Vitti, G.C., Luz, P.H.C. 2010. Manejo da adubação potássica na cultura da cana-deaçúcar. Revista Brasileira de Ciência do Solo 34(4): 1137-1145.

Pavinato, P. S., Ceretta, C. A., Girotto, E., Moreira, I. C. L. 2008. Nitrogênio e potássio em milho irrigado: análise técnica e econômica da fertilização. Ciência Rural 38:358-364.

Petter, F.A., Silva, J.A., Pacheco, L.P., Almeida, F.A., Alcântara Neto, F., Zuffo, A.M., Lima, L.B. 2012. Desempenho agronômico da soja a doses e épocas de aplicação de potássio no Cerrado piauiense. Revista Ciências Agrárias 55(3): 190196.

Possamai, J.M., Souza, C.M., Galvão, J.C.C. 2001. Sistemas de preparo do solo para o cultivo do milho safrinha. Bragantia 60(2): 79-82.

Rabêlo, F.H.S., Rezende, A.V., Rabelo, C.H.S., Amorim, F.A. 2013. Características agronômicas e bromatológicas do milho submetido a adubações com potássio na produção de silagem. Revista Ciência Agronômica 44(3): 635643.

Sousa, J.V., Rodrigues, C.R., Luz, J.M.Q., Carvalho, P.C., Rodrigues, T.M., Brito C.H. 2010. Silicato de potássio via foliar no milho: fotossíntese, crescimento e produtividade. Bioscience Journal 26(4): 502-513.

Valderrama, M., Buzetti, S., Benett, C. G. S., Andreotti, M., Teixeira Filho, M. C. M. 2011 . Fontes e doses de NPK em milho irrigado sob plantio direto. Pesquisa Agropecuária Tropical 41:254263.

Viana, E.M., Kiehl, J.C. 2010. Doses de nitrogênio e potássio no crescimento do trigo. Bragantia 69(4): 975-982.

Von Pinho, R.G., Borges, I.D., Pereira, J.L.A.R., Reis, M.C. 2009. Marcha de absorção de macronutrientes e acúmulo de matéria seca em milho. Revista Brasileira de Milho e Sorgo 8(2): 157-173. 